\title{
A Critical Study and Comparative Analysis of Various Haze Removal Techniques
}

\author{
Dilraj Kaur \\ Dept. of CSE \\ CT Institute Of Engineering Management and \\ Technology, Jalandhar
}

\begin{abstract}
Fog is just a combination of two parts airlight and direct attenuation; it reduces the image quality and produces big quantity of problems in video monitoring, monitoring and navigation. Therefore, to eliminate it from an image, several defogging methods have been planned in literature. Defogging may be performed applying different photos and single image haze treatment strategy. That paper presents a review on the different haze treatment methods. These methods are generally utilized in several programs for instance outdoor monitoring, subject detection, electronic devices etc. The overall objective with this paper has gone to investigate the different practices for efficiently eliminating the haze from digital images. It's been explored that nearly all the prevailing researchers have neglected several dilemmas; i.e. no approach is exact for various kind of circumstances.
\end{abstract}

\section{General Terms}

Critical study for various haze removal techniques

\section{Keywords}

Visibility Restoration, Fog Removal, Dark Channel Prior.

\section{INTRODUCTION}

Visibility restoration [1] refers to different ways that help to reduce and remove the degradation which occurs when a digital image is taken. The image suffers from degradation due to various reasons such as relative object-camera motion, blur due to camera misfocus, relative atmospheric turbulence etc. The main cause of image degradation is due to bad weather conditions such as fog, haze, rain and snow . During Fog, when we take an image using a camera then the light gets scattered before reaching the camera due to some impurities in the atmosphere. Due to this, automatic monitoring system, outdoor recognition system and intelligent transportation system are badly affected. Scattering of light is caused by two fundamental phenomena such as attenuation and airlight. By using haze removal algorithms, we can enhance the stability and robustness of the visual system. Removal of haze is a difficult task because fog depends upon the unknown scene depth information. Fog effect is defined as event of distance between camera and object. Hence removal of fog requires the estimation of airlight map or depth map. The haze removal techniques can be classified into two categories: image enhancement and image restoration. Image enhancement doesn't include the reason why fog degrades image quality. This technique enhances the contrast of haze image but it leads to loss of information in image.

\author{
Pooja \\ Dept. of CSE \\ CT Institute Of Engineering Management and \\ Technology, Jalandhar
}
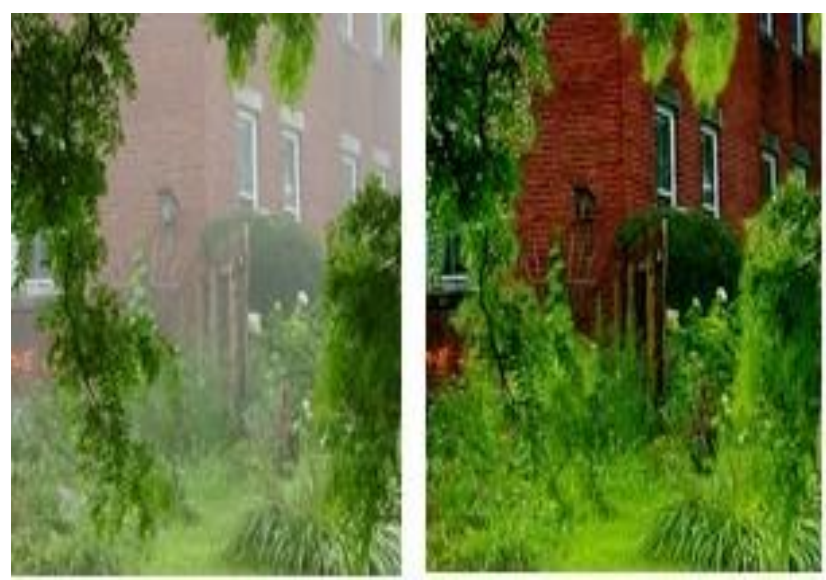

Fig 1[(13)]: (a) Original image (b) Processed image

Image restoration studies the physical procedure of imaging in fog. After observing degradation style of fog, image will undoubtedly be established. At last, the degradation process is used to produce the fog free image.

\section{VISIBILITY RESTORATION TECHNIQUES}

Various image restoration techniques are as follows:

\subsection{Dark channel prior}

Dark channel prior [3] has been developed to estimate atmospheric light in the dehazed image so as to produce the output image. This technique is basically used for non-sky patches, as at least one color channel has surprisingly low intensity at some pixels. The intensity is reduced due to three components:-

Colourful items or surfaces(green grass, tree, blooms and so on)

$>$ Shadows(shadows of car, buildings etc)

Dark items or surfaces(dark tree trunk, stone )

Since the outdoor images are usually filled with shadows and colors, the dark channels of these images also become dark. Due to this, fog (airlight), a haze image is brighter than its image without haze. Thus, dark channel of haze image has higher intensity in region with higher haze. So, intensity of dark channel is a rough approximation of the thickness of haze. In dark channel prior we can also use pre and post processing steps for recovering results. In post processing we 
can use soft matting or bilateral filtering etc. Let $\mathrm{J}(\mathrm{x})$ be an input image, $I(x)$ is foggy image, $t(x)$ could be the transmission of the medium. The attenuation of image due to fog can be expressed as:

$I_{a t t}(x)=J(x) t(x)$

the effect of fog IS Airlight effect and it is expressed as:

$I_{\text {airlight }}(x)=A(1-t(x))$

Dark channel for an arbitrary image $\mathbf{J}$, expressed as $\mathbf{J}$ dark is defined as:

$J^{\operatorname{dark}}(x)=\frac{\min }{y \in \Omega(x)}\left(\min J^{C}(Y)\right)$
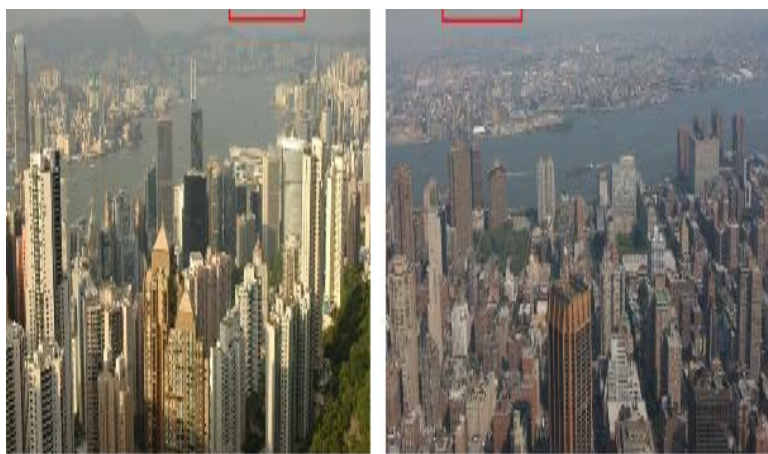

Figure 2.a([3]) Haze removal : Input Haze Image
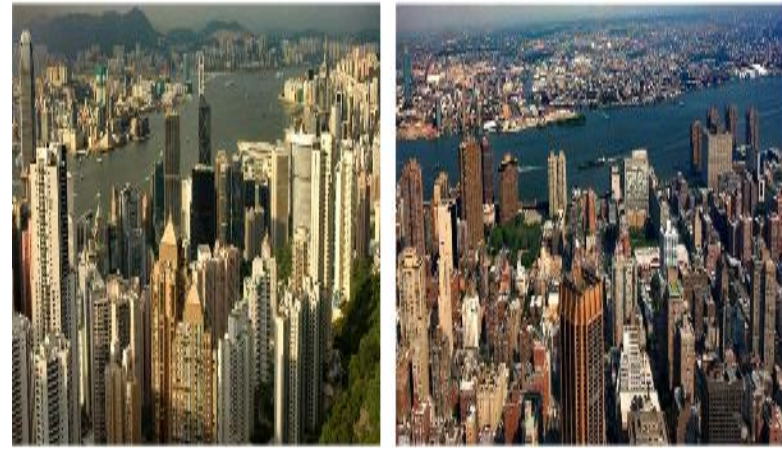

Figure 2.b([3]) Haze removal :Restored Hazefree Image
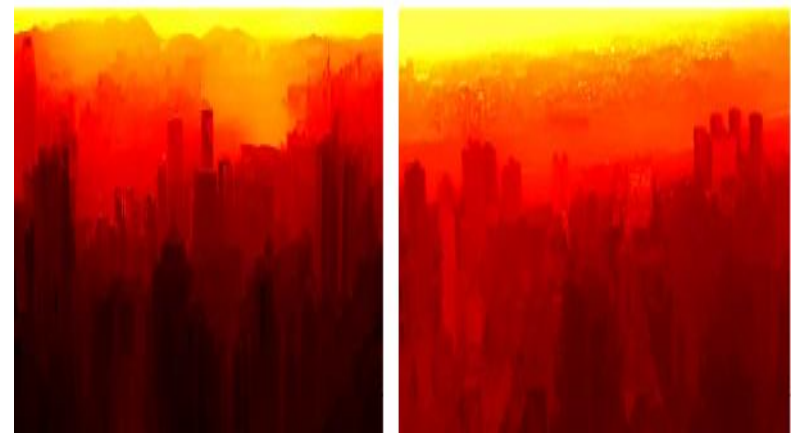

Figure2.c:Haze removal results([3])Top: input haze images. Middle: restored haze-free images. Bottom: depth maps.
In this $\mathbf{J}^{\mathrm{c}} \mathrm{s}$ the color image comprising of RGB components, represents a nearby patch which has its origin at $\mathrm{x}$. The reduced intensity of dark channels is attributed mainly due to shadows in images, saturated color objects and dark objects in images. After dark channel prior, we have estimated transmission $\mathrm{t}(\mathrm{x})$ for proceeding further with the solution. Another assumption needed is that let Atmospheric light A is also known. (4) is normalized by dividing both sides by A:

$\frac{I^{c}}{A^{c}}(x)=\mathrm{t}(\mathrm{x}) \frac{J^{c}}{A^{c}}(x)+1-\mathrm{t}(\mathrm{x})$

\subsection{Clahe}

Contrast limited adaptive histogram equalization CLAHE [1] does not want any predicted weather information for the processing of hazed image. Firstly, the image is captured by the camera in foggy condition and then converted from RGB (red, green and blue) color space to HSI (hue, saturation and intensity) color space. The images are converted because the human sense colors similarly as HSI represent colors. Secondly intensity component is processed by CLAHE without affecting hue and saturation. This process use histogram equalization on a contextual region. Firstly, histogram is clipped and the clipped pixels are redistributed to each gray-level. In this each pixel intensity is shortened to maxima of user selectable. Finally, the image processed in HSI color space is converted back to RGB color space.

It is a generalization of Adaptive Histogram Equalization (AHE). CLAHE differs from ordinary AHE in its contrast limiting. CLAHE limits the amplification by clipping the histogram at a user-defined value called clip limit. The clipping level determines how much noise in the histogram should be smoothed and hence how much the contrast should be enhanced. A variation of the contrast limited technique called adaptive histogram clip (AHC) can also be applied. AHC automatically adjusts clipping level and moderates overenhancement of background regions of images. One of the AHC that normally used is Rayleigh distribution which produces a bell-shaped histogram.

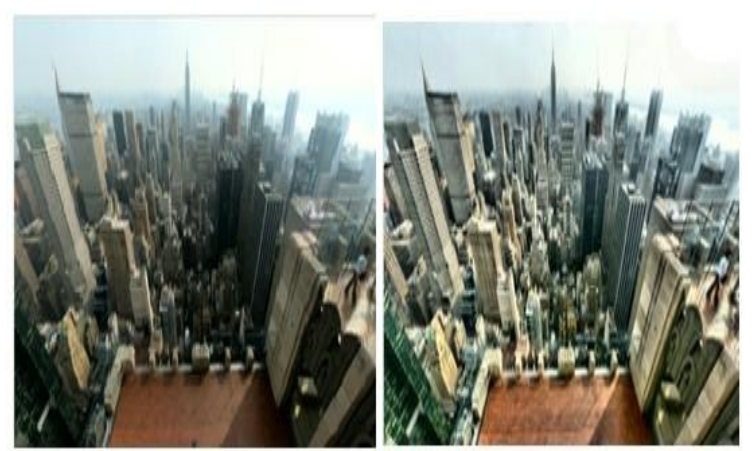

Figure 3 resultant image using CLAHE method([1]): (a) input image(b) output image

The function is given by

$$
\text { Rayleigh }_{g}=g_{\min }+\left[2 \alpha^{2} \ln \left(\frac{1}{1-P(f)}\right)\right]^{0.5}
$$

where $\mathrm{g}_{\min }$ is a minimum pixel value, $\mathrm{P}(\mathrm{f})$ is a cumulative probability distribution and $\alpha$ is a nonnegative real scalar specifying a distribution parameter. In this study, clip limit is set to 0:01 and $\alpha$ value in Rayleigh distribution function is set to 0:04.

\subsection{Wiener filtering}

Wiener filtering is based on dark channel prior: Wiener filtering [5] is used to counter the issues such as color 
distortion while using dark channel prior when the images with large white area is processed. When using dark channel prior the worth of media function is rough which create halo effect in final image. So, median filtering is employed to estimate the media function, so that edges can be preserved. After making the median function more accurate it's along with wiener filtering so that the image restoration problem is transformed into optimization problem. This algorithm is used to recover the contrast of a large white area for image. The running time of image algorithm is also less.

\subsection{Bilateral filtering}

Bilateral Filtering [2] smoothes images while preserving edges, by means of a non-linear mixture of nearby image values. In this, filter replaces each pixel by weighted averages of its neighbour's pixel. The weight given to each neighbour pixel decreases with both the distance in the image plane and the distance on the intensity axis. This filter produces faster results. While using the bilateral filter we can use preprocessing and post processing steps for better results. Histogram equalization is used as pre-processing and histogram stretching as an article processing. These steps help to improve the contrast of image before and after usage of bilateral filter. This algorithm is independent of density of fog thus,it works on on the images taken in dense fog. It generally does not require user intervention. It is applicable in tracking and navigation, consumer electronics and entertainment industries.
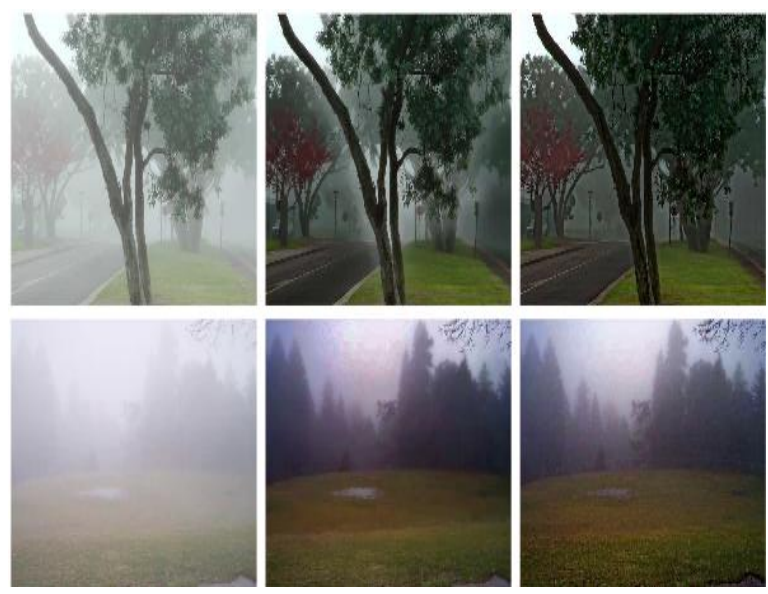

Figure 4 Weiner defogged image([5]): (a) Original foggy image (b) Defogged image (c) Weiner defogged image
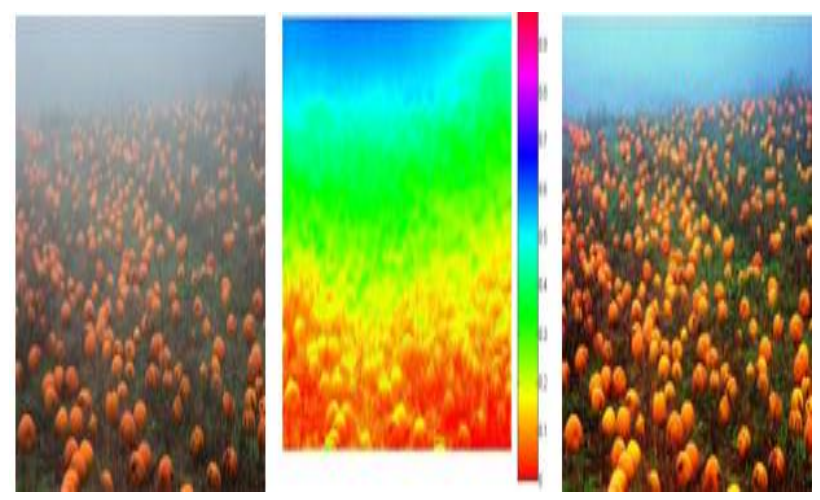

Figure 5 Image filtering using bilateral filter ([2]): (a) original foggy 'pumpkins' image, (b) corresponding air light map using bilateral filter, and (c) Restored image

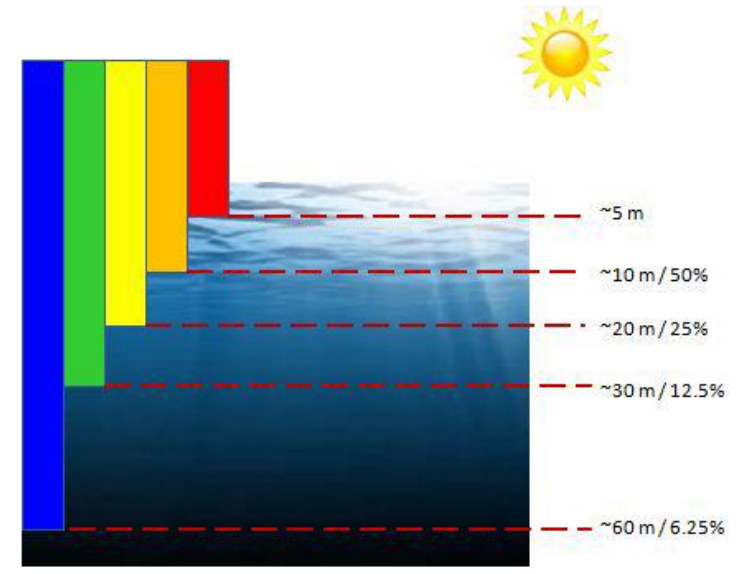

Figure 6: Absorption of light by water ([12])

Figure 6 shows an illustration about the absorption of light

\subsection{Mix-CLAHE}

Hitam et al. (2013) [15] presented method to improve contrast of underwater images by using a mixture Contrast Limited Adaptive Histogram Equalization. The enhancement method enhances the visibility of underwater images and produces the best MSE and the PSNR values. Thus, it proves that the mix-CLAHE based method is promising for classifying coral reefs particularly when visual cues are visible.

The proposed CLAHE-Mix first normalize the result of CLAHE-RGB

$R G B_{n}=\left[\sqrt{r_{c_{1}}^{2}+r_{c_{2}}^{2}}, \sqrt{g_{c_{1}}^{2}+g_{c_{2}}^{2}}, \sqrt{b_{c_{1}}^{2}+b_{c_{2}}^{2}}\right] \ldots$

Conversion of RGB to HSV and HSV to RGB is shown by above variables.

by water. For each $10 \mathrm{~m}$ increase in depth the brightness of sunlight will drop by half. The majority of red light is fully gone by $50 \%$ from the outer lining but blue continues to great depth. That's why most underwater images are dominated by blue-green coloration. CLAHE-Mix first normalizes caused by CLAHE-RGB.

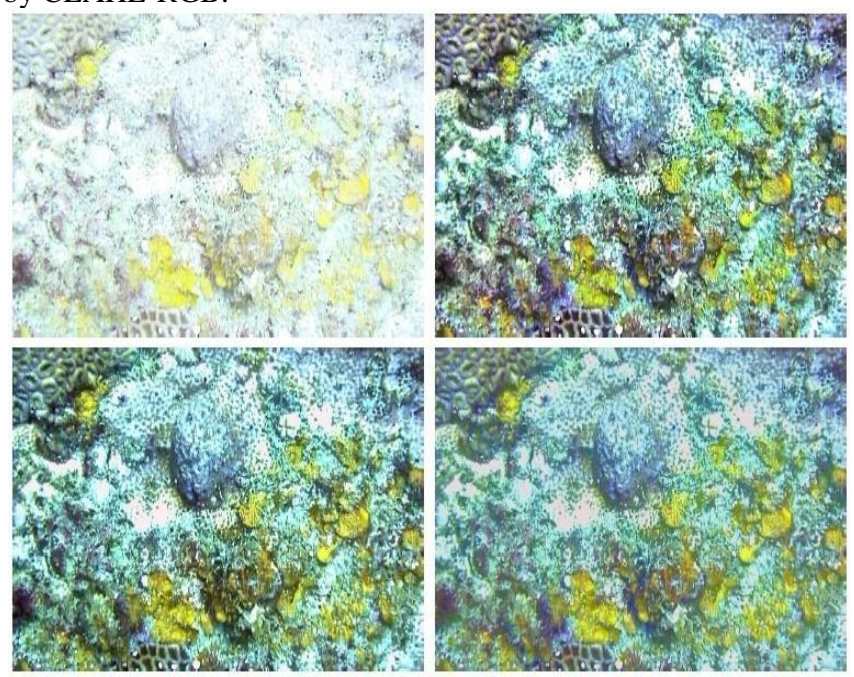

Figure 7: Comparison of CLAHE methods on image([12]). Upper left: original underwater image. Upper right: CLAHE-RGB image. Bottom left: CLAHE-HSV image. Bottom right: CLAHE-Mix image. 


\section{COMPARATIVE ANALYSIS TABLE}

Table 1 shows the comparison of the various haze removal techniques.

Table 1: Comparison of various haze removal techniques

\begin{tabular}{|c|c|c|c|c|c|}
\hline S. NO. & AUTHORS & YEAR & TECHNIQUES & FEATURES & LIMITATIONS \\
\hline [1] & $\begin{array}{l}\text { Xu, Zhiyuan, Xiaoming } \\
\text { Liu, and Na Ji } \\
\text { [IEEE] }\end{array}$ & 2009 & $\begin{array}{l}\text { Contrast Limited Adaptive } \\
\text { Histogram Equalization }\end{array}$ & $\begin{array}{l}\text { Effective in comparison } \\
\text { with traditional methods }\end{array}$ & $\begin{array}{l}\text { Neglected the } \\
\text { techniques to reduce the } \\
\text { noise issue }\end{array}$ \\
\hline [2] & $\begin{array}{l}\text { Tripathi, A. K., and S. } \\
\text { Mukhopadhyay } \\
\text { [IEEE] }\end{array}$ & 2012 & $\begin{array}{l}\text { fog removal algorithm } \\
\text { bilateral filter }\end{array}$ & $\begin{array}{l}\text { independent of the } \\
\text { density of fog and does } \\
\text { not require user } \\
\text { intervention }\end{array}$ & $\begin{array}{l}\text { Not much effort has } \\
\text { focused on the } \\
\text { integrated approach of } \\
\text { the AHE and ACO }\end{array}$ \\
\hline [3] & $\begin{array}{l}\text { Wang, Yan, and Bo Wu } \\
\text { [IEEE] }\end{array}$ & 2010 & local dark channel prior & $\begin{array}{l}\text { obtain more accurate } \\
\text { result }\end{array}$ & $\begin{array}{l}\text { The problem of the } \\
\text { uneven illuminate is } \\
\text { also neglected }\end{array}$ \\
\hline [4] & $\begin{array}{l}\text { Yu, Jing, and Qingmin } \\
\text { Liao } \\
\text { [IEEE] }\end{array}$ & 2011 & atmospheric scattering model & $\begin{array}{l}\text { achieves good } \\
\text { restoration for contrast } \\
\text { and color fidelity }\end{array}$ & $\begin{array}{l}\text { Neglected the } \\
\text { techniques to reduce the } \\
\text { noise issue }\end{array}$ \\
\hline [5] & $\begin{array}{l}\text { Shuai, Yanjuan, Rui } \\
\text { Liu, and Wenzhang } \\
\text { He[IEEE] }\end{array}$ & 2012 & $\begin{array}{l}\text { wiener filtering based on } \\
\text { dark channel prior }\end{array}$ & shortens the running time & $\begin{array}{l}\text { The problem of the } \\
\text { uneven illuminate is } \\
\text { also neglected }\end{array}$ \\
\hline [6] & $\begin{array}{l}\text { Cheng, F-C., C-H. Lin, } \\
\text { and J-L. Lin }\end{array}$ & 2012 & lowest level channel prior & $\begin{array}{l}\text { utilises the exact } O(1) \\
\text { bilateral filter for high } \\
\text { performance }\end{array}$ & $\begin{array}{l}\text { The problem of the } \\
\text { uneven illuminate is } \\
\text { also neglected }\end{array}$ \\
\hline [7] & $\begin{array}{l}\text { Xu, Haoran } \\
\text { [IEEE] }\end{array}$ & 2012 & $\begin{array}{l}\text { fast bilateral filtering } \\
\text { combined with dark colors } \\
\text { prior }\end{array}$ & $\begin{array}{l}\text { improve the adaptability } \\
\text { and fast execution speed }\end{array}$ & $\begin{array}{l}\text { Neglected the } \\
\text { techniques to reduce the } \\
\text { noise issue }\end{array}$ \\
\hline [8] & $\begin{array}{l}\text { Sahu, Jyoti } \\
\text { [International journal2] }\end{array}$ & 2012 & $\begin{array}{l}\text { color image contrast Fog } \\
\text { removing algorithm }\end{array}$ & $\begin{array}{l}\text { efficient and reliable } \\
\text { choice for fog removing }\end{array}$ & $\begin{array}{l}\text { The problem of the } \\
\text { uneven illuminate is } \\
\text { also neglected }\end{array}$ \\
\hline [9] & $\begin{array}{l}\text { Matlin, Erik, and } \\
\text { PeymanMilanfar }\end{array}$ & 2012 & $\begin{array}{l}\text { iterative, adaptive, non- } \\
\text { parametric regression } \\
\text { method. }\end{array}$ & denoise the image & $\begin{array}{l}\text { The problem of the } \\
\text { uneven illuminate is } \\
\text { also neglected }\end{array}$ \\
\hline [10] & $\begin{array}{l}\text { Kang, Li-Wei, Chia- } \\
\text { Wen Lin, and Yu- } \\
\text { Hsiang Fu. } \\
\text { [IEEE] }\end{array}$ & 2012 & $\begin{array}{l}\text { single-image-based rain } \\
\text { removal framework }\end{array}$ & $\begin{array}{l}\text { preserves most original } \\
\text { image details }\end{array}$ & $\begin{array}{l}\text { Neglected the } \\
\text { techniques to reduce the } \\
\text { noise issue }\end{array}$ \\
\hline [11] & $\begin{array}{l}\text { Yuk, Jacky Shun-Cho, } \\
\text { and Kwan-Yee Kenneth } \\
\text { Wong }\end{array}$ & 2012 & $\begin{array}{l}\text { foreground decremental } \\
\text { preconditioned conjugate } \\
\text { gradient }\end{array}$ & $\begin{array}{l}\text { effectively improve the } \\
\text { visualization quality }\end{array}$ & $\begin{array}{l}\text { The problem of the } \\
\text { uneven illuminate is } \\
\text { also neglected }\end{array}$ \\
\hline [12] & $\begin{array}{l}\text { Hitam, M. S., W. N. J. } \\
\text { H. W. Yussof, E. A. } \\
\text { Awalludin, and Z. } \\
\text { Bachok }\end{array}$ & 2013 & $\begin{array}{l}\text { mixture Contrast Limited } \\
\text { Adaptive Histogram } \\
\text { Equalization }\end{array}$ & $\begin{array}{l}\text { improves the visual } \\
\text { quality of underwater } \\
\text { images }\end{array}$ & $\begin{array}{l}\text { The problem of the } \\
\text { uneven illuminate is } \\
\text { also neglected }\end{array}$ \\
\hline$[21]$ & $\begin{array}{l}\text { Huang, Darong, Zhou } \\
\text { Fang, Ling Zhao, and } \\
\text { Xiaoyan Chu. }\end{array}$ & 2014 & dark channel prior & $\begin{array}{l}\text { restore the fogging } \\
\text { image effectively and } \\
\text { reduce the time }\end{array}$ & $\begin{array}{l}\text { Neglected the } \\
\text { techniques to reduce the } \\
\text { noise issue }\end{array}$ \\
\hline
\end{tabular}




\begin{tabular}{|l|l|l|l|l|l|}
\hline$[22]$ & $\begin{array}{l}\text { Ghani, Ahmad } \\
\text { Shahrizan Abdul, and } \\
\text { Nor Ashidi Mat Isa. }\end{array}$ & 2015 & Rayleigh distribution & $\begin{array}{l}\text { complexity } \\
\text { enhances the image } \\
\text { contrast, reduces the } \\
\text { blue-green effect, and } \\
\text { minimizes under- and } \\
\text { over-enhanced areas in } \\
\text { the output image }\end{array}$ & $\begin{array}{l}\text { The problem of the } \\
\text { uneven illuminate is } \\
\text { also neglected }\end{array}$ \\
\hline$[23]$ & $\begin{array}{l}\text { Wang, Jin-Bao, Ning } \\
\text { He, Lu-Lu Zhang, and } \\
\text { Ke Lu. }\end{array}$ & 2015 & dark channel prior & $\begin{array}{l}\text { improve the operational } \\
\text { efficiency }\end{array}$ & $\begin{array}{l}\text { Neglected the } \\
\text { techniques to reduce the } \\
\text { noise issue }\end{array}$ \\
\hline
\end{tabular}

\section{CONCLUSION AND FUTURE WORK}

Fog removal formulas are more helpful for various vision applications. It can be found that many the existing scientific study has neglected alot of issues; i.e. no technique is precise for different circumstances. The review has demonstrated the undeniable fact that shown methods have neglected the methods to reduce the noise concern which can be shown within the output images of the last haze removal algorithms. The issue of uneven and also over illumination may also be an issue for dehazing methods. So it will be expected to change the prevailing methods in this manner that altered strategy may continue steadily to function better. In near future, to eliminate the issues of present research a different integrated algorithm is going to be proposed.

\section{ACKNOWLEDGMENTS}

I would like to thanks god, my family, my teachers, my friends to guide and support me to write this paper. They always help me when I need.

\section{REFERENCES}

[1] Xu, Zhiyuan, Xiaoming Liu, and Na Ji. "Fog removal from color images using contrast limited adaptive histogram equalization." In Image and Signal Processing, 2009. CISP'09. 2nd International Congress on, pp. 1-5. IEEE, 2009.

[2] Tripathi, A. K., and S. Mukhopadhyay. "Single image fog removal using bilateral filter." In Signal Processing, Computing and Control (ISPCC), 2012 IEEE International Conference on, pp. 1-6. IEEE, 2012.

[3] Wang, Yan, and Bo Wu. "Improved single image dehazing using dark channel prior." Intelligent Computing and Intelligent Systems (ICIS), 2010 IEEE International Conference on. Vol. 2. IEEE, 2010.

[4] Yu, Jing, and Qingmin Liao. "Fast single image fog removal using edge-preserving smoothing." Acoustics, Speech and Signal Processing (ICASSP), 2011 IEEE International Conference on. IEEE, 2011.

[5] Shuai, Yanjuan, Rui Liu, and Wenzhang He. "Image Haze Removal of Wiener Filtering Based on Dark Channel Prior." Computational Intelligence and Security (CIS), 2012 Eighth International Conference on. IEEE, 2012.

[6] Cheng, F-C., C-H. Lin, and J-L. Lin. "Constant time O (1) image fog removal using lowest level channel." Electronics Letters 48.22 (2012): 1404-1406.
[7] $\mathrm{Xu}$, Haoran, et al. "Fast image dehazing using improved dark channel prior." Information Science and Technology (ICIST), 2012 International Conference on. IEEE, 2012.

[8] Sahu, Jyoti. "Design a New Methodology for Removing Fog from the Image." International Journal 2 (2012).

[9] Matlin, Erik, and PeymanMilanfar. "Removal of haze and noise from a single image." IS\&T/SPIE Electronic Imaging. International Society for Optics and Photonics, 2012.

[10] Kang, Li-Wei, Chia-Wen Lin, and Yu-Hsiang Fu. "Automatic single-image-based rain streaks removal via image decomposition." Image Processing, IEEE Transactions on 21.4 (2012): 1742-1755.

[11] Yuk, Jacky Shun-Cho, and Kwan-Yee Kenneth Wong. "Adaptive background defogging with foreground decremental preconditioned conjugate gradient." Computer Vision-ACCV 2012. Springer Berlin Heidelberg, 2013. 602-614.

[12] Hitam, M. S., W. N. J. H. W. Yussof, E. A. Awalludin, and Z. Bachok. "Mixture contrast limited adaptive histogram equalization for underwater image enhancement." In Computer Applications Technology (ICCAT), 2013 International Conference on, pp. 1-5. IEEE, 2013.

[13] Chu C.T., Lee M .S. "A Content-Adaptive method for Single Image dehazing"

[14] Xu, Zhiyuan, Xiaoming Liu, and Xiaonan Chen,"Fog removal from video sequences using contrast limited adaptive histogram equalization", Computational Intelligence and Software Engineering, 2009 International Conference on. IEEE, 2009\

[15] Desai, Nachiket, Chatterjee Aritra, Mishra Shaunak and Choudary Sunam, "A Fuzzy Logic Based Approach to De-Weather Fog-Degraded Images", Computer Graphics, Imaging and Visualization, 2009 Sixth International Conference on. IEEE, 2009.

[16] Yu, Jing, Chuangbai Xiao, and Dapeng Li, "Physicsbased fast single image fog removal", Signal Processing (ICSP), 2010 IEEE 10th International Conference on. IEEE, 2010

[17] Guo, Fan, Cai Zixing, Xie Bin and Tang Zin, "Automatic Image Haze Removal Based on Luminance Component", Wireless Communications Networking and Mobile Computing (WiCOM), 2010 6th International Conference on. IEEE, 2010. 
[18] Chu, Chao-Tsung, and Ming-Sui Lee, "A contentadaptive method for single image dehazing", Proceedings of the Advances in multimedia information processing and 11th Pacific Rim conference on Multimedia, Springer-Verlag, 2010.

[19] Xu, Zhiyuan, and Xiaoming Liu, "Bilinear interpolation dynamic histogram equalization for fog-degraded image enhancement", J Inf Comput Sci 7.8 (2010) 1727-1732.

[20] Yu, Jing, and Qingmin Liao, "Fast single image fog removal using edge-preserving smoothing", Acoustics, Speech and Signal Processing (ICASSP), 2011 IEEE International Conference on. IEEE, 2011.
[21] Huang, Darong, Zhou Fang, Ling Zhao, and Xiaoyan Chu. "An improved image clearness algorithm based on dark channel prior." In Control Conference (CCC), 2014 33rd Chinese, pp. 7350-7355. IEEE, 2014.

[22] Ghani, Ahmad Shahrizan Abdul, and Nor Ashidi Mat Isa. "Underwater image quality enhancement through integrated color model with Rayleigh distribution."Applied Soft Computing 27 (2015): 219230.

[23] Wang, Jin-Bao, Ning He, Lu-Lu Zhang, and Ke Lu. "Single image dehazing with a physical model and dark channel prior." Neurocomputing 149 (2015): 718-728. 